\title{
21 \\ QUANTITATIVE INTEGRATION OF THE ANALYTICAL HIERARCHICAL PROCESS AND VIRTUAL ENTERPRISE MODEL TO SUPPORT MANAGER DECISIONS
}

\author{
Giuseppe Confessore \\ Istituto di Tecnologie Industriali e Automazione - Sezione di Roma \\ Consiglio Nazionale delle Ricerche \\ c/o DISP. Via del Politecnico 1, 00133 Roma, Italy \\ g.confessore@itia.mi.cnr.it
}

Livio Cricelli

Università di Cassino. Dipartimento di Meccanica, Strutture, Ambiente e Territorio

Via G. Di Biasio 43, 03043 Cassino (Fr) Italy

cricelli@unicas.it

Paolo Mancuso

Università di Roma "Tor Vergata". Dipartimento di Informatica, Sistemi e Produzione

Via del Politecnico 1, 00133 Roma, Italy

mancuso@disp.uniroma2.it

\begin{abstract}
In measuring the global performance of a production system two problems are relevant. The first one is represented by the individuation of a meaningful set of indicators and the second one by the choice of the connected weights system. In this paper, we highlights the advantages of the integration of the Analytical Hierarchical Process and the use of a simulation tool of a production system. The procedure of such integration is explained with more considerations given to its possible dual application, by top managers and systems' designers, to firstly predict the possible changes of production system and then take reasonable courses of action to individuate the best configuration. Moreover, we have tested the proposed methodology for an Italian firm.
\end{abstract}

\section{INTRODUCTION}

One of the most relevant topics in production management is the development of integrated systems which are able to co-ordinate different technologies and applications; aiming at making the whole process of production efficient. In a competitive environment, industrial enterprises must continuously improve their productivity to sustain long term growth and profitability. To increase efficiency, without absorbing further resources, productivity measurement and analysis can 
therefore play an important role in the strategic planning and competitive analysis (Lowlor, 1985, Sudit, 1995).

In many industrial sectors, models of business management that are based on the maximisation of the short run profits are often inadequate to guarantee success in front of changes in the world competitive markets. The problems faced today by each firm have reached high level of unforeseeably and complexity, and so, as a result, the decisions that the managers must take result in hard determination. For a long time management has turned their own attention toward two different directions:

1. to the inside, where the purpose is to improve the processes of production to adjust them to the mutable situations of market and new technologies and to modify the organisational structures, policies and the techniques of management;

2. to the outside, where they try to modify the market, arouse new needs or modify those existing to exploit the action of the competitors and the behavior of the institutions.

To develop their own activity effectively management needs continuous information on the whole economic system and on their own operational units. Difficulties that it meets to effect the correct choices are highly correlated to the quantity and the quality of available information (Avai et al, 2001). It appears therefore evident that the presence of a rational and efficient information system is essential for the existence and the survival of the firm.

The purpose of the information system is therefore to develop a continuous function of control both on the inside environment, constituted by varied business activities, and on the outside environment, represented by the competitors, the institutions and the consumers. The core of the system is represented by the performance measurement system that assumes therefore a fundamental importance in the optimal management of the firm and for its existence and survival.

The term performance has recently entered in the common political and managerial language, to indicate the achieved result obtained by any activities. More precisely, with performance, it is the intended result of management of the activities of an organization in a certain period of time (Lucertini et al, 1995, Hatry, 1980). This interpretation doesn't allow the deepest meaning that the performance assumes in business circles; it is not a simple numerical value. Having performance implicates to have success, to be competitive, to be able to react opportunely to the changes of the external environment and individualizing and improving those activities which are able to provide value to the firm. The performance of a firm today is the key to economic success.

In this sense, the concept of performance is deeply linked to management. In fact, Lebas (1995) shows that performance doesn't refer to the results provided in the past, but rather is projected toward those obtainable in the future, introducing in this way the concept of performance management. Management must, in practice, individualize the causes of performance and to pursue continuous improvement, supported by the measures of the same performance. In fact, the comprehension of the processes of performance generation not only facilitates the identification of these measures and therefore the possible corrective actions, but it allows a clear utilization of strategies to each level of responsibility. 
The performance management precedes and follows the performance measurement in a repetitive loop, creating at the same time the environment for the measures. A system of effective performance management must be supported by measures that (Lebas, 1995):

a) give autonomy to managers;

b) reflect relationships of cause and effect;

c) create the bases for the discussion, so supporting continuous improvement;

d) help managers in making their decisions.

The performance management and the measurement of performance can not be separated; if we focus only on the measurements, without understanding that the measures are the consequences of the decisions, we loose the opportunity to reach the control on the processes of performance creation and success for the firm (Prokopenko, 1992). The measurement concept is considered an essential prerequisite getting efficient results and continuously improving business performances. The concept of performance evaluation has always existed; traditionally the measurements were based on historical data, almost never on competitive bases or through the use of financial indicators. These last ones are able to be drawn only after the editing of budgets and therefore they are not able to signal opportunely the presence of problems. The actual market conditions and the firms global competition make these indicators insufficient to obtain a measure of efficiency and we must move attention toward the search for new indexes to measure business performances. The individuation of the proper criterions to evaluate the results really obtained by the firm is still object of researchers discussion. In the literature, in fact, a unique reference model doesn't exist. In general, it depends on the particular considered context and from the specific sector of application. The most diffused and used criterions for performance evaluation (indexes, variations, ratios, etc.) fall into the categories of effectiveness, productive efficiency, and profitability. The significance of this paper can be seen in the definition of framework to evaluate the operative, tactical and strategic decisions of the management. We propose to use the analytical hierarchical process (Saaty, 1977, Saaty and Khouja, 1977, Saaty and Varga, 1979) to evaluate the decisions where the weights of the decision tree are computed by using a simulation model of the production system. To do this, we introduce the concept of virtual enterprise (or virtual factory - VF) as the simulation model of the physical enterprise (or physical factory - PF).

\section{THE MODEL}

To allow the management to decide which are the best decisions, at operative, tactical and strategic level, we introduce a model in which an analytical hierarchical process tool is integrate with a simulation model representing the physical enterprise (see Figure 1).

In particular, in the simulation model (or virtual enterprise) we simulate the different scenarios originated from different decisions of the management (the different choices that the decision tool has to evaluate) for computing the weights necessary to order the choices by decision tool. The virtual enterprise is a virtual copy of the physical enterprise. The physical and informative flows that are involved in the 
physical enterprise are represented in the virtual enterprise by entity flow in the simulation model.

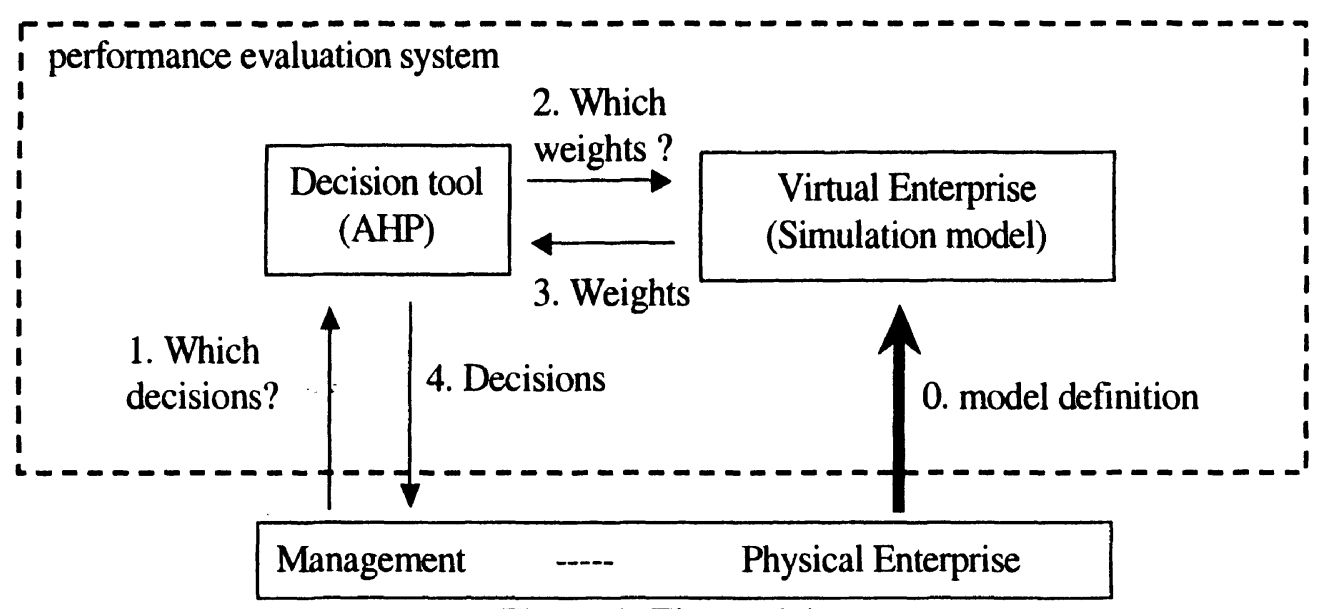

Figure 1. The model.

When a decision has to be make, different choice are make in the simulation model. Then, it is possible to set the weights of the decision tree in order to choice the best decision. The decision could be strategic, tactical or operative, even in the same time.

\section{A CASE STUDY}

The theoretical model defined in section 2 has been applied at one of the most important Italian industry, at world-wide level of domestic appliances. We have considered three productive plants employed for the production of electric compressors for refrigerators. The three plants are located in different part of the North East of Italy. The first plant located near Pordenone produces copper and castiron for electric motors and compressors. The second plant in Rovigo assembles electric motors. Finally, the last plant near Belluno assembles the compressors.

At this point our analysis has been focussed on Rovigo plant characterised by a jobshop productive configuration. In particular we have considered two manufacturing departments in which stators and rotors are produced respectively. Then the performance indicators and their relative weights have been obtained through interviews with plant managers and using the AHP methodology (Chankong and Haimes, 1983, Mesarovich et al., 1970) implemented by Expert Choices ${ }^{\circledR} 2000$ software (see Table 1).

Performance indicators specification for each nodes level is reported below (note that the numbers 1 and 2 are referred at the two manufacturing departments).

- First level nodes: $\operatorname{Pr}=$ Productivity, Production Environment $=\mathrm{PE}, \mathrm{CS}=$ Customer Satisfaction, Lo = Logistic

- Second level nodes: LP = Labour Productivity, MP = Machinery Productvity, FI $=$ Flexibility, $\mathrm{Ma}=$ Maintenance, $\mathrm{TO}=$ Time to Order, $\mathrm{LT}=$ Production Lead Time, MLT $=$ Mean Lead Time stock-out, MDT = Mean Delivery Time. 
- Third level nodes: LE = Labour Efficiency (total amount of actually worked hour/total amount of paid hours), LPE $=$ Labour Performance (produced volume/total amount of effective worked hours), $\mathrm{ME}=$ Machinery Efficiency (actually production hours/scheduled production hours machines), MPE = Machines Performance (produced volume/(actually production hours), PN= Number of different products, MST $=$ Mean Set-up Time, MTBF $=$ Mean Time Between Failure, MTM = Mean Time to Maintenance, PLT $=$ Production Lead Time, $\mathrm{TLT}=$ Transport Lead Time, WLT $=$ Waiting Lead Time

- Fourth level nodes: MSTS = Mean Set-up Time between the production of items belonging to the same products typology, MSTD $=$ Mean Set-up Time between the production of items belonging to different products typology.

The second step in our analysis has been the individuation of the strategic scenarios to compare. The base scenario has been obtained starting from the production data collected during the 2000 year. The production level reached in this year has been about 3 millions of compressors. Moreover, in order to consider the existence of seasonality the production period has been divided into two sub-periods: November to April and May to October. The total amount of compressors produced has been of 1.200.000 in the first period and 1.800 .000 in the second one. The collected data have been normalised and reported in Table 2 .

Table 1. Performance indicators and weights.

First level Second level Third level

nodes

$\operatorname{Pr} 0.25$

nodes

LP 0.33

Pr

\begin{tabular}{|c|c|c|}
\hline & MP 0.66 & ME 0.5 \\
\hline & & MPE 0.5 \\
\hline PE 0.25 & Fl 0.389 & $\begin{array}{l}\text { PN } 0.469 \\
\text { MST } 0.531\end{array}$ \\
\hline & Ma 0.611 & $\begin{array}{l}\text { MTBF } 0.434 \\
\text { MTM } 0.566\end{array}$ \\
\hline CS 0.25 & $\begin{array}{l}\text { TO } 0.524 \\
\text { LT } 0.476\end{array}$ & $\begin{array}{l}\text { PLT } 0.723 \\
\text { TLT } 0.277 \\
\text { WLT } 0.146 \\
\text { PLT } 0.61 \\
\text { TLT } 0.244\end{array}$ \\
\hline
\end{tabular}

Lo 0.25

MLT0.12

MDT 0.88

$\begin{array}{cc}\begin{array}{c}\text { Fourth level } \\ \text { nodes }\end{array} & \begin{array}{c}\text { Fifth level } \\ \text { nodes }\end{array}\end{array}$

LE1 0.545

LE2 0.455

LPE1 0.545

LPE2 0.455

ME1 0.6

ME2 0.4

MPE1 0.6

MPE2 0.4

MSTS $0.525 \quad$ MSTS1 0.545

MSTS2 0.455

MSTD 0.475 MSTD1 0.545

MSTD2 0.455

MTBF1 0.5

MTBF2 0.5

MTM1 0.566

MTM2 0.434 
Table 2. Performance indicators values

\begin{tabular}{|lcc|}
\hline Performance indicators & First period & Second Period \\
\hline LE1 & 0.958 & 0.958 \\
LE2 & 0.958 & 0.958 \\
LPE1 & 0.28 & 0.563 \\
LPE2 & 0.28 & 0.564 \\
ME1 & 0.937 & 0.937 \\
ME2 & 0.917 & 0.917 \\
MPE1 & 0.388 & 0.643 \\
MPE2 & 0.409 & 0.669 \\
PN & 0.25 & 0.25 \\
MSTS1 & 0.545 & 0.5 \\
MSTS2 & 0.455 & 0.625 \\
MSTD1 & 0.545 & 0.3 \\
MSTD2 & 0.455 & 0.3 \\
MTBF1 & 0.475 & 0.475 \\
MTBF2 & 0.5 & 0.5 \\
MTM1 & 0.333 & 0.333 \\
MTM2 & 0.25 & 0.25 \\
PLT & 0.45 & 0.75 \\
TLT & 0.5 & 0.5 \\
WLT & 0.6 & 0.6 \\
MLT & 0.45 & 0.75 \\
MDT & 0.6 & 0.6 \\
\hline
\end{tabular}

The alternative scenarios are four and they are characterised by different assumption on firm's strategic objective, obtained using the virtual enterprise simulated through the discrete simulation software tool ARENA ${ }^{\circledR}$. In the first scenario, the performance indicators modified respect to the base scenario are relative to Productivity (Pr) and Production Environment (PE); in the second Customer Satisfaction (CS); in the third Customer Satisfaction (CS) and Logistic (L) and in the last one, only the change in the Production Environment (PE) has been examined. The modified values of the indicators under the different scenario, computed by the simulation tool, are shown below:

First Scenario:

\begin{tabular}{|lcc|}
\hline Performance indicators & First period & Second Period \\
\hline LPE1 & 0.35 & 0.7 \\
LPE2 & 0.35 & 0.7 \\
MPE1 & 0.45 & 0.8 \\
MPE2 & 0.45 & 0.8 \\
MSTS1 & 0.8 & 0.8 \\
MSTS2 & 0.8 & 0.8 \\
MTM1 & 0.5 & 0.5 \\
MTM2 & 0.4 & 0.4 \\
\hline
\end{tabular}

Second Scenario:

\begin{tabular}{|lcc|}
\hline Performance indicators & First period & Second Period \\
\hline PLT & 0.75 & 0.9 \\
\hline
\end{tabular}


Third Scenario:

\begin{tabular}{|lcc|}
\hline Performance indicators & First period & Second Period \\
\hline PLT & 0.5 & 0.8 \\
TLT & 0.7 & 0.7 \\
WLT & 0.65 & 0.65 \\
MLT & 0.5 & 0.8 \\
MDT & 0.65 & 0.65 \\
\hline
\end{tabular}

Fourth Scenario:

\begin{tabular}{|lcc|}
\hline Performance indicators & First period & Second Period \\
\hline PN & 0.5 & 0.5 \\
MSTS1 & 0.6 & 0.6 \\
MSTS2 & 0.6 & 0.6 \\
MSTD1 & 0.6 & 0.6 \\
MSTD2 & 0.6 & 0.6 \\
MTBF1 & 0.6 & 0.6 \\
MTBF2 & 0.6 & 0.6 \\
MTM1 & 0.5 & 0.5 \\
MTM2 & 0.4 & 0.4 \\
\hline
\end{tabular}

The global alternatives priority computed by the Software Expert Choices ${ }^{\circledR} 2000$ in the two production periods are summarised in Table 3.

Table 3: Global alternatives priority

\begin{tabular}{|l|c|c|}
\hline Alternatives & First Period & Second Period \\
\hline Base Alternative & 0.183 & 0.188 \\
\hline Alternative 1 & 0.197 & 0.203 \\
\hline Alternative 2 & 0.222 & 0.203 \\
\hline Alternative 3 & 0.195 & 0.199 \\
\hline Alternative 4 & 0.203 & 0.207 \\
\hline
\end{tabular}

The model results for the first production period are shown in Figure 2. The best alternative is the second one, that is proposed to improve exclusively the production lead time. Also differing from the actual situation only for an indicator (PLT), the obtained improvement in the global performance is very high (about $21 \%$ ). In fact, the production lead time influences in decisive way the internal logistic and also the customer satisfaction. With the aim to evaluate the importance of the first level weights, a sensitivity analysis is performed. As it is shown in Figure 3, for a value of productivity weight equal to $70 \%$ the alternatives are equivalents. Therefore, if this objective can become such strategically important in near future, it would be necessary to proceed to a more detailed analysis in order to estimate better which alternative to follow. Moreover variations in all strategic objectives weights within a enough wide range do not involve appreciable differences in the choice of the best alternative. 


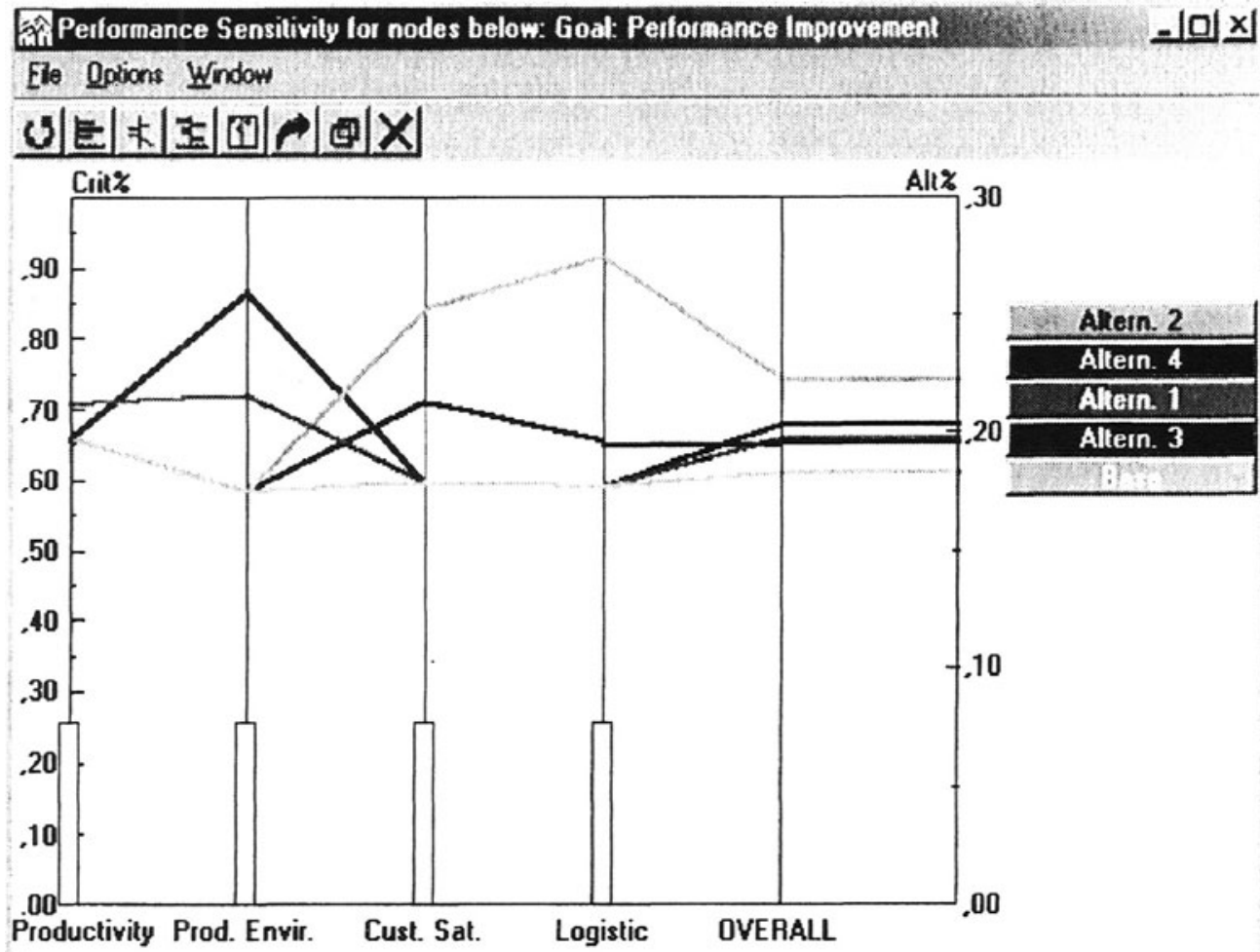

Sensitivity w.r.t.: Goal: Performance Improvement

Figure 2: Performance Graph for the first production period.

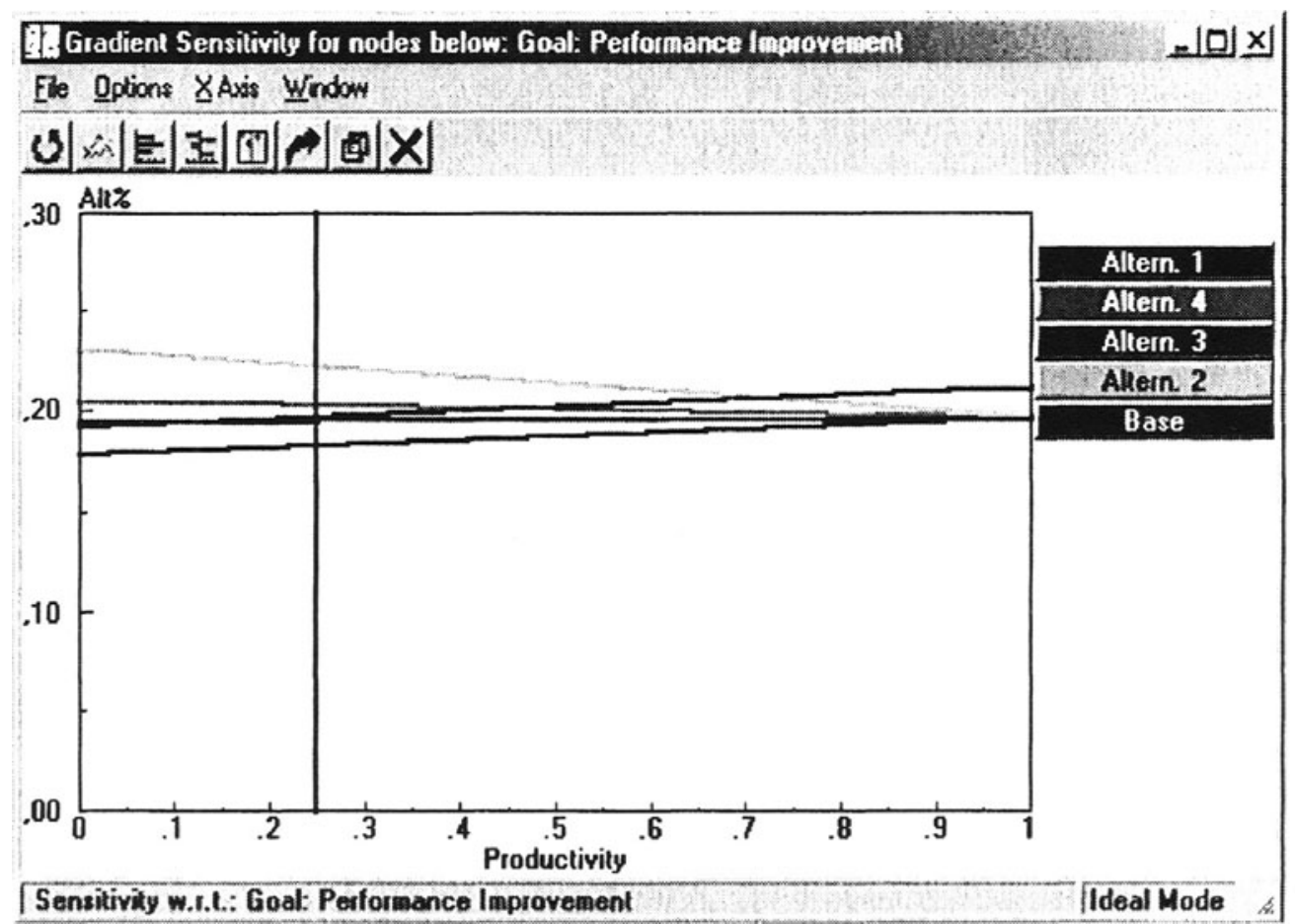

Figure 3: Sensitivity Analysis Graph for productivity 
In the second period (see Figure 4), characterized from a large volume of production, the examined alternatives cause not very high improvements in the global performance respect the actual situation.

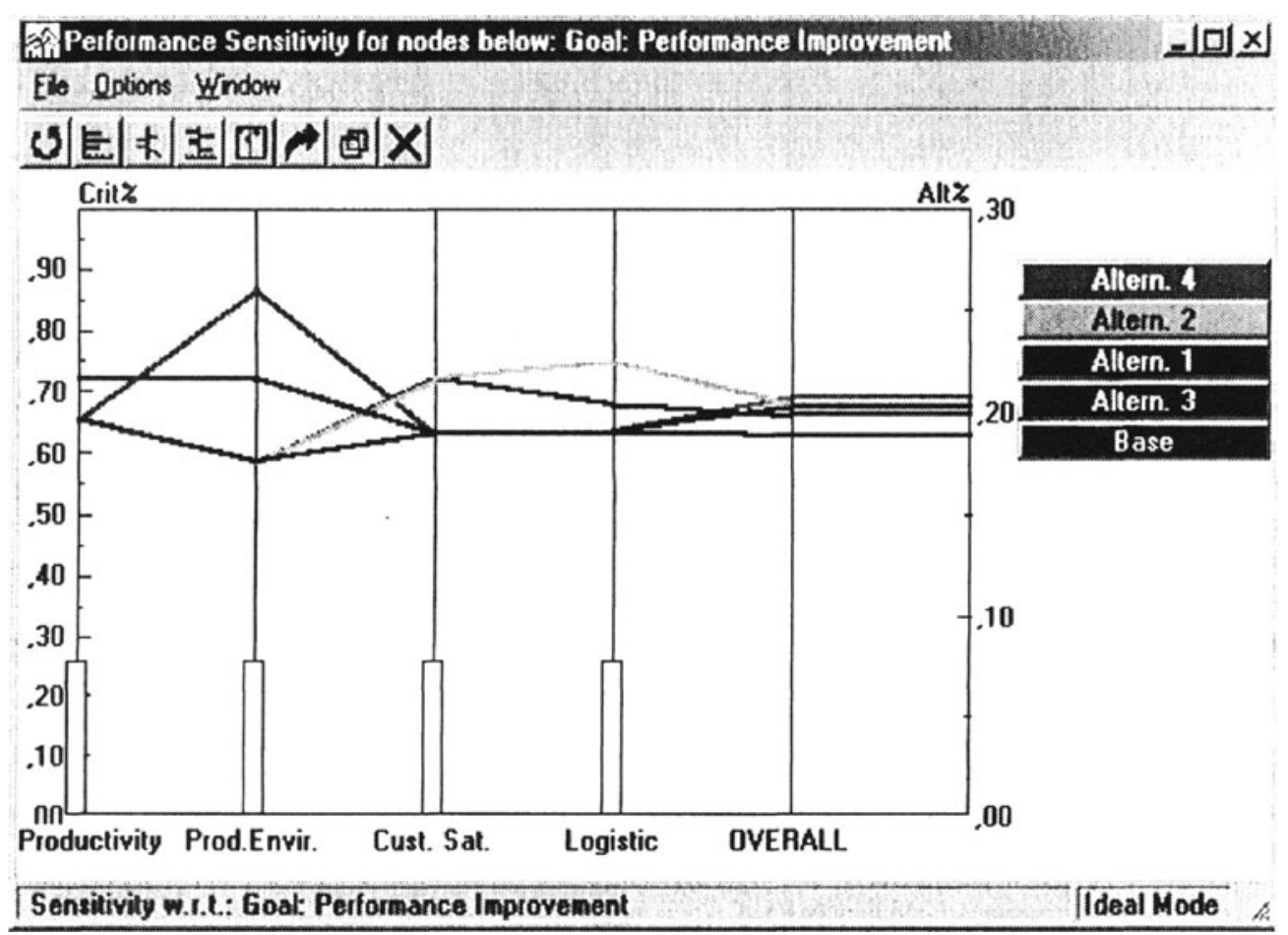

Figure 4: Performance Graph for the second production period.

\section{CONCLUSIONS}

In this paper we have introduced an integrated procedure based on the analytical hierarchical process methodology and the discrete simulation software in order to allows the management to take decisions. In particular, we have introduced an operational framework to evaluate the operative, tactical and strategic decisions of the management. So, after the simulation model of a plant has been designed, we have generated four scenarios characterized by different assumptions on firm's strategies. Then for each scenario the performance indicators have been computed in the simulation environment and, finally, the best scenario has been individuated through AHP methodology.

Preliminary results related to a plant of an Italian firm shown that our approach is useful when different decisions at different levels are taken in the same time. The next steps will be the following:

to improve the simulation model of the production system in order to obtain a better definition of the performance indicators ;

to extend the proposed analysis to the whole supply chain of the domestic appliances. 


\section{REFERENCES}

1. Avai A., Boer C. R., Carotenuto P., Confessore G., Fornasiero R., "A Performance Indicators Model for the Supply Chain", in Pawar and Muffatto Eds. Logitics and the Digital Economy, University of Nottingham, pp. 315-320, 2001.

2. Chankong V. and Haimes Y.Y. "Multiobjective decision making. Theory and methodology" NorthHolland, 1983.

3. Hatry H. P. "Performance measurement principles and techniques: an overview for local government", Public Productivity Review, 4, 312-339, 1980.

4. Lebas M.J., "Performance Measurement and Performance Management", International Journal of Production Economics, 23-35, 1995.

5. Lowlor A., "Productivity Improvement Manaul", Gower Publ., 1985.

6. Lucertini M. , Nicolò F. and Telmon D., "Integration of Benchmarking and Benchmarking of Integration", International Journal of Production Economics, 38, 58-71, 1995.

7. Mesarovich M.D., Macko D. and Takayama Y. "Theory of Hierarchical, Multilevel Systems", Academic Press, New York, 1970.

8. Prokopenko J., "La gestione della Produttività", Franco Angeli/Azienda Moderna Ed., 1992.

9. Saaty T.L., "Scaling method for priorities in hierarchical Structures", Journal of Mathematical Psychology, 15, n. 3, 1977.

10. Saaty T.L. and Khouja M.A., "A measure of world influence”, Peace Science, 1977.

11. Saaty T.L. and Varga L.G. "Estimating technological coefficients by the analytic hierarchy process", Socio-Econ. Plan. Sci., 13, pp. 333-336, 1979.

12. Sudit E.F. "Productivity measurement in industrial operations", Invited review, European Journal of Operational Research, 85, 435-453, 1995. 